\title{
13 Big tech's push for norms to tackle uncertainty in cyberspace
}

\author{
Jacqueline Eggenschwiler
}

Reports about large-scale data breaches, critical infrastructure hacks, and malware strikes targeting public and private systems and network infrastructures have become ubiquitous. Given the political and economic ramifications of these malicious activities conducted by both state and non-state actors - global security and prosperity are highly dependent on secure and stable ICTs and networks - governments have sought to stipulate behavior-guiding rules of the road for cyberspace by means of international conferences and expert processes. Progress and agreement on norms of responsible behavior for cyberspace, however, have been slow and unwieldy (Hampson et al. 2017). Disputes among government entities about how and if existing international rules apply to cyberspace have provided flourishing breeding beds for private norm ventures (Väljataga 2017; Henriksen 2019; Korzak 2017). Since the non-consensus outcome of the United Nations Group of Governmental Experts on Developments in the Field of Information and Telecommunications in the Context of International Security (UN GGE) in 2017, corporate as well as other non-state entities have started to more actively insert their voices in debates about rules of the road for the digital domain (Sukumar 2017; Henriksen 2019). ${ }^{1}$

This chapter examines the norms-based cyber insecurity reduction measures initiated by corporate actors. In particular, it summarizes and comments on the effectiveness of the normative strategies pursued by technology companies, including Kaspersky Lab, Siemens, Telefónica, and Microsoft. For the purposes of this chapter, technology companies are understood to denote enterprises engaging in and deriving sizeable percentages of their revenues from the development, manufacturing, and maintenance of technology products and services, including, for instance, hard- and software components and platform services. The selection of the four case studies was informed by geographical (companies displaying different national origins: Russia, Europe, the United States) as well as substantive considerations (companies having made active reference to, proposed, or joined norms-based policy instruments).

Scholarly literatures in the fields of international relations and international law have taken note of the behavior-shaping powers exerted by private entities across different policy areas since at least the early 1990s (Ruggie 2004; Nye and Donahue 2000; Finnemore and Sikkink 1998). In the context of cyber security, 
however, performance-oriented assessments of the norms-based activities proposed by non-state actors and their implications for global governance processes have remained sparse. Seeking to address this void, this chapter argues that while the norms-based activities carried out by technology companies have been effective at opening up debates and influencing political processes, their efforts have borne less fruit apropos decreasing systemic levels of cyber insecurity. As long as governments lack the political will to truly follow through on their commitments to make cyberspace more stable and secure, and engage in concerted efforts with private agents, the fact that corporate activities have not managed to reduce systemic levels of cyber insecurity should not come as a surprise.

The lack of systemic change should be even less astonishing if it is accepted that norms constitute what Cristina Bicchieri termed as conditional rules

such that individuals prefer to conform when they expect a sufficiently large proportion of the population to conform (coordination or "empirical expectation"), and they believe that a sufficiently large proportion of the population might sanction them if they [do not] (fear of sanction or "normative expectation").

(Carbonara 2017: 468)

Arguably, the proportion of conforming agents in cyberspace is not yet sufficiently large enough to invoke shared normative expectations at systemic levels. Cyber operations have provided useful tools for governments and proxy actors "to achieve strategic objectives both covertly and overtly", and have offered much room for maneuver, which they are (now) hesitant to give up (Leuprecht et al. 2019: 402).

Even so, it is critical to appreciate and better understand the normative strategies pursued by non-state actors and resulting consequences. As per Hegemann and others, "[m]any of the core issues and problems of international politics require answers to questions of whether, how, and when certain actors, tools, or policies cause or at least affect specific results" (Hegemann et al. 2012: 15). With a view to supporting critical analyses of the activities undertaken by relevant actors and devising potential alternatives, it is vital to study the consequences of said activities, and the extent to which they have accomplished specified goals (Hegemann et al. 2012: 15). Given the market power of the technology companies flagged above, as well as their economic and political credence, and vocal participation in cyber security norm formation processes, examinations pertaining to the effectiveness of their efforts appear to be particularly pressing.

Methodologically, this contribution relies on secondary sources in the fields of international relations and international law, with a focus on governance-relevant texts, as well as primary sources, including press releases, reports, and audiovisual materials, issued by industry protagonists concerned with promoting norms of responsible behavior in cyberspace.

The remainder of this chapter is organized along three sections. The first section provides contextual information related to the topic under investigation, 
recaps important developments, and specifies central concepts. The second section examines and appraises the contributions of technology companies to global cyber security norm development processes. Finally, the third section sums up the findings and highlights avenues for further progress.

\section{Cyber security and norms}

Early internet pioneers, including John Perry Barlow, regarded cyberspace as a virtual environment not requiring formal rules or external controls (Barlow 1996). However, growing numbers of cyber security events affecting private as well as public information and communication technologies (ICTs) have undermined these non-interventionist positions. Over the course of the past two decades, voluntary norms of responsible behavior "have emerged along with confidence- and capacity-building measures as the principal policy tools of choice to meet the [...] vision of an open, secure, accessible, and peaceful ICT environment" (Kavanagh 2017: 10).

Defined as shared expectations of appropriate behavior, norms can be of regulative (i.e. describing obligations, prohibitions and permissions) or constitutive (i.e. creating categories of actors and actions) nature (Finnemore and Sikkink 1998; Wiener 2017; Björkdahl 2002). "By shaping agents' understandings of their social environments, associated interactions, and possible outcomes", they foster coordination and predictability, and in turn reduce contextual ambiguities to manageable levels (Ferguson 2019: 1). In contrast to formal legal provisions, norms rely on softer means of enforcement and implementation. ${ }^{2}$

According to Finnemore, the move to voluntary cyber security norms can partly be attributed to concerns about the suitability and effectiveness of binding treaties in fast-moving environments, as well as to fears of legal lock-in among leading cyber powers (Finnemore 2017: 3). Abbot and Snidal have argued that

when circumstances are fundamentally uncertain, that is, when even the range and/or distribution of possible outcomes is unknown, [formal legal agreements] may not be desirable. In particular, if actors are ambiguity-averse, they will prefer to leave agreements imprecise rather than face the possibility of being caught in unfavorable commitments.

(Abbott and Snidal 2000: 442)

Despite perceived needs to reduce threats and corresponding levels of uncertainty, and more than two decades of concerted diplomatic efforts relating to the formulation of norms of responsible behavior for the digital domain, advancement has been slow and political compromise short-lived. In the wake of political contentions among governments surrounding debates about existing and emerging perils emanating from the digital realm and possible normative measures to address them, a number of non-state actors have stepped up and started to more actively make their voices heard (Grigsby 2017; Mačák 2017; Väljataga 2017). 
International relations and international law literatures have taken note of the rise of private actors involved in global steering and rule-making processes, and have systematized and subsumed ideational efforts conducted by non-state actors under the umbrella of norm-entrepreneurship or soft-law, respectively (Finnemore and Sikkink 1998; Risse-Kappen, Ropp, and Sikkink 1999; Abbott and Snidal 2000). Norm entrepreneurs (or protagonists of soft-law instruments) challenge prevailing patterns of behavior, by suggesting normative ideas and mobilizing like-minded stakeholders or networks within and across states to endorse them (Sandholtz 2017: 2). "These alliances [then] bring pressure to bear from above (transnationally) and below (domestically)", and help the standards proposed get more widely accepted (Sandholtz 2017: 2).

Following the non-consensus outcome of the 2017 UN GGE and an accumulation of cyber security incidents of transnational magnitude, including WannaCry and Petya/NotPetya, entrepreneurial activities undertaken by non-state actors in the context of fostering responsible behavior in cyberspace have grown considerably (Hinck 2018; Mačák 2017). The period between February 2017 and November 2018 saw the launch of at least nine different initiatives/proposals. ${ }^{3}$ Although noteworthy, in terms of consistency, accountability, and authority, these proposals have contributed to heightened levels of fragmentation (Dunn Cavelty and Wenger 2020). Not only have non-state actors created additional or even competing norm formation processes but they have also set foot in traditionally statedriven domains. Yet, in view of lingering hesitations on the parts of governments apropos meaningfully enforcing existing cyber security norms, trends of fragmentation may be useful in increasing awareness about cyber security norms and widening stakeholder participation across different streams. As per Ruhl and others,

[d]ifferent processes may be optimised for different kinds of outcomes - in terms of the actors and activities. Norms may be more realistic in some areas than in others, such as peacetime use of cyber capabilities compared with military cyber operations. Having multiple processes can prevent a roadblock in one area from impeding all progress.

(Ruhl et al. 2020: 13)

In order to reap the benefits of these fragmented processes, however, initiators need to deliberately plan for "complementarity" and "cross-pollination".

The next section summarizes leading norms-based efforts launched by Microsoft, Siemens, Telefónica, and Kaspersky Lab, and assesses the effectiveness of their activities along three dimensions: Output, outcome, and impact. Analyzing the effects of regulatory efforts has remained extremely challenging and has incited numerous scholarly debates. There are no unified approaches for assessing the success of norms or regimes. This chapter draws on the work conducted by Flohr et al. and Wolf who have proposed assessments along the dimensions mentioned above (Flohr et al. 2010; Wolf 2010). Only proposals with explicit normative nexus and only proposals launched post-2017 were selected for analysis. 


\section{Private cyber security norm development efforts}

Non-state actors, in particular technology companies, have been key contributors to the development and expansion of cyberspace. ${ }^{4}$ As operators of network infrastructures, designers of products, and suppliers of services, they have made important contributions to the "international [...] architecture for the governance of cyberspace" (Radu 2014: 4). In addition to producing hard- and software, they have come to contribute to the promotion of global cyber security norms and standards. So far, their normative contributions have received little academic attention. This chapter seeks to contribute to richer understandings of the normative parts played by technology companies and unveil the governing qualities of their activities by evaluating them across the dimensions of output, outcome, and impact. ${ }^{5}$

As key providers of ICTs, technology companies have strong incentives to pursue normative strategies to sustain their business models. Through the eyes of technology companies, norms provide useful tools for tackling contextual ambiguities and pre-empt costly changes to legal frameworks, or governmentled market interventions. While the reasons for corporate norm-shaping efforts pertaining to the virtual realm may primarily be grounded in commercial considerations, i.e. reducing costs and risks, securing their operations, gaining access to new markets/safeguarding existing customer bases, and strengthening corporate reputation and legitimacy, less self-serving reasons, i.e. upholding good-faithcommitments and values such as user privacy, should not be forgotten (Gorwa and Peez 2018). Not all of the activities undertaken by technology companies in the context of norms of responsible behavior for cyberspace can be explained by rationalist arguments.

\section{Microsoft}

One of the first corporate entities to engage in debates about responsible conduct in cyberspace was Microsoft (Microsoft Security Response Center 2010). Valued at over USD 1 trillion (2019), the company ranks among the four largest technology giants globally, the other three being Apple, Alphabet, and Amazon. Following prior norms-oriented ventures between 2013 and 2016, in February 2017, Microsoft President and Chief Legal Officer Brad Smith introduced the idea of a Digital Geneva Convention to Protect Cyberspace (Microsoft 2013; McKay et al. 2014; Charney et al. 2016; Smith 2017). Grounded in the belief that deeprooted collaboration among states, and between states, the private sector, and civil society is needed to curb nefarious doings in the digital realm, the convention as outlined by Smith, asks governments, among other things, to:

- Refrain from attacking critical infrastructures (including civil and financial systems)

- Abstain from engaging in espionage

- Engage in vulnerabilities disclosure processes 
- Exercise restraint in developing cyber weapons and engaging in offensive activities, and

- Assist private sector entities in securing cyberspace. (Microsoft 2017)

It also calls on technology companies to behave as neutral actors and recommends the setting up of an independent non-governmental organization capable of investigating and publicly attributing (nation-state) cyberattacks (Smith 2017; Maurer and Taylor 2018). Met with little enthusiasm by governments, Microsoft's call for a Digital Geneva Convention was succeeded by the unveiling of a Cybersecurity Tech Accord bringing together "global technology companies committed to protecting their customers and users", 14 months later. ${ }^{6}$

In September 2018, Microsoft unveiled a Digital Peace Now campaign, which calls on citizens to protect cyberspace, e.g. through measures of cyber hygiene, and urges governments to refrain from endangering the global digital environment (Microsoft 2018). Only two months later, Microsoft co-sponsored the Paris Call for Trust and Security in Cyberspace. Introduced at the 12th Internet Governance Forum (IGF) in Paris, the Paris Call for Trust and Security in Cyberspace (short Paris Call) constitutes one of the most widely endorsed multi-stakeholder instruments pertaining to peace and security in the virtual realm to date (Ministère de l'Europe et des Affaires Étrangères 2018).

The Paris Call proposes the development of common principles for securing cyberspace through collaborative efforts across existing international platforms and mechanisms (Ministère de l'Europe et des Affaires Étrangères 2018). Although at first sight a French initiative, the Paris Call was vitally influenced by Microsoft, both in terms of origin and content. According to information presented by Le Monde and WIRED, it was Microsoft's political lobbying that gave rise to the initiation of the Paris Call (Matsakis 2018a; Untersinger 2018). The Paris Call advances nine principles intended to resonate with both state and nonstate entities. Specifically, it asks supporters to:

- Prevent and recover from malicious cyber activities that threaten or cause significant, indiscriminate or systemic harm to individuals and critical infrastructure;

- Prevent activity that intentionally and substantially damages the general availability or integrity of the public core of the Internet;

- Strengthen our capacity to prevent malign interference by foreign actors aimed at undermining electoral processes through malicious cyber activities;

- Prevent ICT-enabled theft of intellectual property, including trade secrets or other confidential business information, with the intent of providing competitive advantages to companies or commercial sector;

- Develop ways to prevent the proliferation of malicious ICT tools and practices intended to cause harm;

- Strengthen the security of digital processes, products and services, throughout their lifecycle and supply chain; 
- Support efforts to strengthen an advanced cyber hygiene for all actors;

- Take steps to prevent non-State actors, including the private sector, from hacking-back, for their own purposes or those of other non-state actors;

- Promote the widespread acceptance and implementation of international norms of responsible behavior as well as confidence-building measures in cyberspace.

(Ministère de l'Europe et des Affaires Étrangères 2018)

Rather than reinventing the wheel in terms of normative prescriptions, the Paris Call constitutes an attempt at realigning scattered discussions and improving the complementarity of cyber security norm formation processes.

While the Paris Call has seen fairly broad uptake among governments, private industry, the technical community, researchers, non-governmental organizations, and civil society, there have been a number of notable public abstentions, including the United States, Russia, China, Iran, and Israel (Matsakis 2018b).

\section{Siemens}

Subsequent to several large-scale cyber security incidents, including WannaCry and Petya/NotPetya, Siemens, together with eight partner corporations issued a Charter of Trust for the digital domain at the sidelines of the 2018 Munich Security Conference (Hern 2017; European Commission 2018). Recognizing that cyber security is a critical enabler for further economic growth and transformation, Charter signatories vouched to (re-)instill confidence in digital technologies and services.

Since its launch in February 2018, the number of sponsors has grown from nine to seventeen Charter partners, and four associate members. The list of current (as of May 2020) supporters includes: Siemens and the Munich Security Conference, AES, Airbus, Allianz, Atos, Cisco, Dell Technologies, Deutsche Telekom, Enel, IBM, Infineon Technologies AG, Mitsubishi Heavy Industries, NXP, NTT, SGS, Total and TÜV Süd, as well as the German Federal Office for Information Security (BSI), the CCN National Cryptologic Centre of Spain, the Graz University of Technology, and the Hasso Plattner Institute for Digital Engineering GmbH (HPI) (Siemens 2019a).

Committing to undertake "every effort to protect the data and assets of both individuals and businesses, prevent damage to people, businesses, and infrastructures and build a reliable basis for trust in a connected and digital world", Charter members have called for binding rules and standards, and close collaboration between civil society, governments, business enterprises, and customers (Siemens 2018a: 1).

With the intention of reducing uncertainty in the virtual realm and enabling trusted interactions, the signatories have advanced ten principles, spanning from ownership of cyber and IT security, responsibility throughout the digital supply chain, security by default, user-centricity, innovation and co-creation, 
to education, certification for critical infrastructure and solutions, transparency and response, regulatory framework, and joint initiatives (Siemens 2018b; Hinck 2018; Kaeser 2018). Multistakeholder in nature, the principles put forward by the Charter signatories are skewed toward key tenets of responsible product development and engineering practices (Horenbeeck et al. 2019).

As part of the ten areas of action identified, Principle 2, i.e. responsibility throughout the digital supply chain, has so far seen most specification. ${ }^{7}$ According to a press release issued by Siemens in February 2019, underwriters have committed themselves to devising baseline requirements pertaining to third-party risks in supply chains and have pledged implementation of measures including:

- The protection of data from unauthorized access throughout the data lifecycle

- The enactment and enforcement of identity and access controls and monitoring measures across supply chains

- The putting into place of processes ensuring product and service authenticity and identification, and

- The deployment of regular employee security trainings

With a view to disseminating their efforts, Charter members have engaged in several round table activities, and endorsed related initiatives, including the Paris Call for Trust and Security in Cyberspace.

\section{Telefónica}

On 25 June 2018, global telecommunications provider Telefónica published the second edition of its Digital Manifesto. ${ }^{8}$ Building on the idea of a social contract, the Manifesto holds that in order to keep reaping the benefits of digital technologies, it is necessary to modernize policies and norms to ensure fair competition and innovation. To that end, a Digital Constitution, a new Digital Bill of Rights to protect key human values and fundamental rights is required. Such a contract, so Telefónica, needs to be as human-centric as possible and rest on the involvement and support of as many stakeholders as possible (Haas 2018).

Revolving around five core principles, Telefónica's Manifesto for a New Digital Deal maintains that:

- Digitalization should be an inclusive process, in which everyone is able to participate

- Social and fiscal policies have to be adapted to the realities of current market conditions and digital companies

- Users ought to have transparent knowledge of and control over their data and corresponding use thereof

- Global providers of digital services should act responsibly and be committed to social development

- Social policy and citizens' rights have to be modernized. (Telefónica 2018) 
In contrast to the normative instruments launched by Microsoft and Siemens, Telefónica's Manifesto for a New Digital Deal is not open to accession by other signatories. Telefónica is, however, a supporter of initiatives, including, for example, the Paris Call for Trust and Security in Cyberspace or the Cybersecurity Tech Accord.

\section{Kaspersky Lab}

With a customer base of more than 400 million users, more than 30 subsidiaries, and revenues of over USD 726 million, Kaspersky Lab ranks among the largest privately owned cyber security companies worldwide (Kaspersky Lab 2019a). In recent years, the company has come under scrutiny for alleged collaboration with the Russian government. In response to accusations of collusion with the Kremlin and fading levels of trust as well as operational bans, Kaspersky Lab launched a Global Transparency Initiative in late 2018.

As per Kaspersky Lab's own attestation, the Global Transparency Initiative (GTI) represents

a reaffirmation of the company's commitment to earning and maintaining the trust of its most important stakeholders: its customers. It includes a number of actionable and concrete measures to involve external independent cyber security experts and others in validating and verifying the trustworthiness of the company's products, its internal processes and business operations, and to introduce additional accountability mechanisms by which the company can further demonstrate that it addresses any security issues promptly and thoroughly.

(Kaspersky Lab 2019b)

In terms of scope and depth, Kaspersky Lab's GTI appears to stand out and differ from comparable benchmarks. Competitor McAfee, for instance, decided to shut down its source-code review programs in 2017 out of fear of foreign interference and vulnerability identification/abuse. ${ }^{9}$ In the remit of the GTI, Kaspersky Lab has recently relocated its data processing and storage units from Russia to Switzerland, and has established four transparency centers, located in Zurich (Switzerland), Madrid (Spain), Cyberjaya (Malaysia), and São Paulo (Brazil). The latter serve as dedicated sites for independent reviews of source code, software updates, threat detection rules, and other technical and business processes by external parties, including regulators and government agencies responsible for cyber security, as well as enterprise partners of Kaspersky Lab (Kaspersky Lab 2020).

Rather than advocating a distinct set of norms or action areas, Kaspersky Lab's norms-oriented activities have primarily revolved around three core principles, i.e. transparency (as the most obvious principle named), trust, and independence, which have emerged in close relation to its operations and issued thirdparty business impediments but, at the same time, appear to reflect larger industry 
trajectories. ${ }^{10}$ Daniel Dobrygowski, Head of Governance and Policy for the World Economic Forum Centre for Cyber Security, for instance, has noted that

over the last few years, tech-focused companies have begun entering into cyber security alliances and pacts with one another. These alliances are a symptom of the breakdown of trust between policy makers and those they [are] making polices for. Hundreds of companies - some of them, such as Airbus, Cisco, HP, Microsoft, Siemens, and Telefónica, among the largest in the world - have tried to step into this trust gap by forming groups around goals related to the future of the internet and digital networks. Some of these groups (... operational alliances) are mainly practical, sharing intelligence or technical data. Others (... normative alliances) are explicitly aimed at changing the ways companies deal with cyber security vulnerabilities and renegotiating the social contract between states and their citizens.

(Dobrygowski 2019: 2)

In contrast to operational alliances, normative alliances pursue wider political aims and try to "uphold values like trust and accountability in cyber security and to spur collective action in favor of peace and nonaggression - much as agreements between countries do" (Dobrygowski 2019: 2). While important momentum-building elements, the efforts pursued by normative alliances, and norm-promoting technology companies more generally, raise important accountability and legitimacy questions. How are corporate norm leaders held accountable for their proposals and implementation thereof, and where do technology companies derive their normative authority from? Rather than by means of formal democratic legitimacy, corporate actors appear to have relied on combinations of functional (functions executed), epistemic (knowledge brokered), and performance (scale and capabilities available) legitimacy to justify their normative endeavors (Peters et al. 2009; Black 2017).

\section{Effectiveness review}

Reviews relating to the effectiveness of the ideational proposals issued by corporate actors concerning cyberspace have remained sparse and difficult to conduct. Nonetheless, such assessments are important yardsticks for making value claims about the contributions of private actors to global steering efforts. This section appraises the consequences of corporate norm formation activities along three dimensions: Output, outcome, and impact (Flohr et al. 2010; Wolf 2010). The three dimensions can be distinguished as follows: Output (category one) refers to identifiable commitments and achievements set by norm entrepreneurs engaging in global steering efforts (Hegemann et al. 2012: 104). They can comprise standards and regulations, programs, as well as institutional structures (Flohr et al. 2010). Performatively linked to category one, category two, outcome, denotes changes in the conduct of participating actors in accordance with the commitments stipulated (Flohr et al. 2010). Impact (category three) relates to contributions to 
Table 13.1 Operationalization of the three effectiveness dimensions

\begin{tabular}{lll}
\hline & Operationalization & \\
\hline Output & $\begin{array}{c}\text { Adoption of commitments and } \\
\text { policies on cyber security-related }\end{array}$ & Accession to collective initiatives \\
issues & $\begin{array}{c}\text { Initiation of proactive measures to } \\
\text { positively influence the level of } \\
\text { Outcome }\end{array}$ & $\begin{array}{c}\text { Change in company-self and the } \\
\text { behavior of third parties and } \\
\text { implementation of initiatives }\end{array}$ \\
Impact & $\begin{array}{c}\text { Reduction of global cyber insecurity } \\
\text { levels }\end{array}$ & $\begin{array}{c}\text { Far-reaching systemic changes } \\
\end{array}$ \\
\hline
\end{tabular}

problem solving or goal attainment resulting from the behavioral alterations of the stakeholders involved.

While categories one (output) and two (outcome) facilitate analyses of nonstate actor functions, category three (impact) enables differentiations between commitments and actions on the one hand and their larger effects on the other (Wolf 2010). Although analytically separated, the three categories, "are closely connected and may even be regarded as parts of a causal chain" (Wolf 2010, 4).

The three dimensions can be operationalized as follows:

In terms of analytical complexity, assessing output is relatively unproblematic, while determining outcome and impact is more demanding. Especially with regard to impact, examining effectiveness is complicated by problems of multicausality, shifting baselines, and counterfactual reasoning (Wolf 2010). The results presented in this chapter have to be understood within the context of these limitations.

\section{Output}

Apropos output, the norms-based cyber insecurity reduction measures undertaken by technology companies have been rather successful. Since the nonconsensus outcome of the 2017 UN GGE, technology companies have released respectable numbers of candidate norms and accompanying advocacy measures. Both in terms of substantive provisions and institutional commitments, firms including Microsoft, Siemens, Telefónica, and Kaspersky Lab have made important contributions to furthering global peace and security in the virtual realm.

The firms' interactions with industry fellows, non-governmental stakeholders, and governments have enabled them to propose widely backed and strategically relevant normative ideas, including, for instance, calls for greater transparency relating to supply chains and products, or widespread protection of critical infrastructures and individuals. 
The measures undertaken by the technology firms have also served as important steppingstones for drawing attention to the ideational proposals of non-state actors more generally and opening up conventional structures of debate. Renata Dwan, Director of the United Nations Institute for Disarmament Research (UNIDIR), for example, has aptly noted that

after being on the UN agenda for over two decades, we are now seeing an expansion on the discussion around what cyber-stability means and for whom. A debate that began focused on state behavior, is now becoming a much wider discussion about the role of the private sector, of regions and of individuals - and how to develop space for rights, for equity, and for access that enhances development for all.

(EastWest Institute 2019)

\section{Outcome}

Vis-à-vis outcome, the technology companies analyzed as part of this chapter, have managed to secure seats at political tables, shape policy agendas, and affect ego and alter behavior. They have committed financial and human resources to their norms-based strategies, and have put in place new organizational setups, including brick and mortar structures to substantiate and implement their norms-based pledges. While Kaspersky Lab, for instance, has invested in the building of transparency centers (brick and mortar structures), Microsoft has bolstered its Digital Diplomacy unit (human resources). With a view to implementing its commitments stipulated as part of the Charter of Trust, Siemens has introduced a binding clause in its new contracts, which requests suppliers to comply with minimum binding cyber security requirements. "These requirements will apply primarily to suppliers of security-critical components such as software, processors and electronic components for certain types of control units. [...] The goal is to better protect the digital supply chain against hacker attacks" (Siemens 2019c).

Furthermore, Siemens and Microsoft have managed to inject their candidate norms into regional and international policy-making processes. ${ }^{11}$ In April 2019, for instance, the Council of the European Union issued a declaration maintaining that

[t]he European Union and its Member States are strongly committed to the existing consensus [around the norms, rules and principles of responsible state behavior as articulated in the cumulative reports of the UN GGE], and to the further discussions in the United Nations, as well as to the commitments made with regard to the protection of intellectual property against cyber-enabled theft in multilateral fora such as G20, or through the Paris Call for Trust and Security in Cyberspace.

(Council of the European Union 2019) 
Through cross-signing initiatives, attending and conducting meetings at the sidelines of major political gatherings, including G7 and G20 meetings, UN-led conventions or major security conferences, technology firms of the likes mentioned above have gained foothold in political arenas and have come to establish themselves as (quasi-)diplomatic actors (Hurel and Lobato 2018b; Gorwa and Peez 2018). ${ }^{12}$

The resonance and uptake of private normative efforts across fora such as the European Union are evidence of their successfully executed roles as norm leaders and also speak to their capacity to promote diplomatic and political changes.

\section{Impact}

Despite advocated broader intentions to increase the stability of the digital realm, the efforts conducted by Siemens, Kaspersky Lab, Telefónica, and Microsoft have not (yet) led to substantial changes apropos minimizing levels of cyber insecurity. Over the course of the past years, cyberattacks have risen continuously. The degrees of damage to the global economy as well as the costs for remediation have accelerated from a projected USD 500 billion, or about $0.7 \%$ of global income, in 2014, to an estimated USD 600 billion, or $0.8 \%$ of global GDP, in 2018. Among others, researchers have quoted the following reasons for the rise in costs:

quick adoption of new technologies by cybercriminals, [a budding] number of new users online (these tend to be from low-income countries with weak cyber security), ... the increased ease of committing cybercrime, with the growth of Cybercrime-as-a-Service, an expanding number of cybercrime centers that now include Brazil, India, North Korea, and Vietnam, [and] a growing financial sophistication among top-tier cybercriminals.

(Lewis 2018: 4)

While the global state of cyber security may have seen little improvement as a consequence of corporate norm development efforts (so far), the activities of global technology companies have at the very least had some broader procedural effects. Their commitment to stipulating responsible behavior in the digital environment has led to greater inclusion of civil society organizations and other private stakeholder in global cyber security problem-solving efforts (Flohr et al. 2010).

\section{Conclusion}

As is evident from the remarks above, technology companies have come to execute different roles in global cyber security norm formation processes. Apart from having acted as brokers of technical knowhow and expertise (knowledge brokers), they have stimulated cooperation among like-minded stakeholders (cooperation incubators), championed norms (norm leaders), and filled procedural as well as content-related gaps (gap fillers). In the face of waning levels of trust in digital 
infrastructures and technologies, it is critical for industry actors to execute their different roles and develop and promote best practices and norms-based interactions in an effort to (re)build confidence and create heightened degrees of predictability in cyberspace.

Against the background of progress-inhibiting discord among governments concerning the enactment of red lines in cyberspace, this chapter has analyzed and appraised the effectiveness of the normative contributions made by technology companies. Exploring the cases of Siemens, Kaspersky Lab, Telefónica, and Microsoft, it has argued that technology companies have come to exert considerable discursive and political power over discussions about responsible behavior in cyberspace. They have generated impressive numbers of candidate norms for increasing the stability and security of the digital realm. Furthermore, they have been successful at signaling their political intentions and promoting/injecting their normative proposals across high-ranking diplomatic venues. While having been fairly effective across the dimensions of output and outcome, technology companies have struggled to effectuate far-reaching systemic changes (impact). However, if incentivized appropriately, and pursued with complementarily in mind, the norms-based endeavors undertaken by technology companies may eventually have the capacity to "have real-world effects on the stability and security of cyberspace" (Ruhl et al. 2020: 19).

As non-state actors continue to be concerned about immediate and future threats to their operations and seek diplomatic engagement, it is important to reconsider existing forms of interaction and cooperation among governmental and non-governmental entities (Melissa Hathaway, in Hampson et al. 2017: 5). In view of the fact that from a formal legal perspective, states are the ultimate enforcers of cyber security norms, it is vital for non-state actors and state actors to work closer together, aid one another in their behavior-shaping efforts, and engage in true cooperation. "[B]roader sets of allies working together to build trust and share responsibility" are more likely to achieve results with systemic effects (Dobrygowski 2019). What appears to be certain at this point is "that the development of cyber security norms [is going to] be a long process", and that persistent engagement on the parts of governments and non-state actors, as well as effective scaling are going to be key factors for success (Nye 2018).

\section{Notes}

1 In the remit of the United Nations, discussions about rules of the road to curb malicious behavior in cyberspace began to surface in the late 1990s. In 2003, in reaction to UN General Assembly Resolution 58/32, a Group of Governmental Experts was called to existence to study existing and emerging threats emanating from the digital realm and possible normative measures to address them. The first of a total of six groups met in 2004. While the three UN GGEs meeting between 2009 and 2015 managed to issue non-binding consensus reports, the two groups convening between 2004-2005 and 2016-2017 did not produce corresponding documents (Väljataga 2017). At the time of writing (November 2019), it remains to be seen whether or not the latest iteration of the UN GGE will arrive at a consensus document. 
2 Finnemore, for instance, noted that "[a]ctors who may feel nervous about being bound by formal laws may be willing to engage with groups governed by norms. Over time, these initially reluctant states, firms and individuals may become socialized into deeper acceptance of the norms" (Finnemore 2011: 90).

3 The initiatives alluded to include the Tallinn Manual 2.0 (NATO Cooperative Cyber Defence Centre of Excellence), the Digital Geneva Convention (Microsoft), the Global Commission on the Stability of Cyberspace (EastWest Institute \& the Hague Centre for Strategic Studies), the Charter of Trust (Siemens), Carnegie Endowment for International Peace's Call for a Global Norm Against Manipulating the Integrity of Financial Data, the Cybersecurity Tech Accord (Microsoft), the Digital Peace Now Campaign (Microsoft), the Paris Call (Microsoft), as well as Kaspersky Lab's Transparency Initiative.

4 Contrary to earlier communication technologies, and despite its emergence in a politically predicated context, sovereign actors initially displayed little inclination toward enacting measures of control over cyberspace. Operation and management of the infrastructure were, for the most part, left to the experts who had contributed to its development, including, among others, Barry M. Leiner, Vinton G. Cerf, David D. Clark, Robert E. Kahn, Leonard Kleinrock, Daniel C. Lynch, Jon Postel, Larry G. Roberts, and Stephen Wolff. Oversight was informal and reflected the academic context within which the digital realm had arisen.

5 Notable exceptions include among others Hurel and Lobato (2018a) and Gorwa and Peez (2018).

6 With a view to defending and advancing the benefits of networked technologies for society, the Cybersecurity Tech Accord calls on private actors to observe four specific principles and behaviors, i.e. to protect all users and customers from nefarious cyber activities, regardless of geographical location, to oppose cyberattacks on civilian and corporate infrastructures, to empower and support users, customers, and developers in their efforts to strengthen cyber security, and to partner with like-minded entities, civil society, and security researchers across proprietary and open source technologies to enhance cyber security.

7 Principle 2 of the Charter of Trust reads as follows: "Companies - and if necessary governments must establish risk-based rules that ensure adequate protection across all IoT layers with clearly defined and mandatory requirements. Ensure confidentiality, authenticity, integrity and availability by setting baseline standards, such as: Identity and access management: Connected devices must have secure identities and safeguarding measures that only allow authorized users and devices to use them. Encryption: Connected devices must ensure confidentiality for data storage and transmission purposes wherever appropriate. Continuous protection: Companies must offer updates, upgrades and patches throughout a reasonable lifecycle for their products, systems and services via a secure update mechanism".

8 The first edition of the Manifesto was launched in 2014 (Telefónica 2014).

9 In contrast, Kaspersky Lab's Transparency Centres welcome "State agencies and regulators responsible for national cyber security and the protection of information systems (decreed as such by the respective local legislation); Prospective and existing enterprise partners and customers of Kaspersky anywhere in the world. Academia, media and information security community experts are being considered as potential invitees to the Transparency Centre in the future. Under no circumstances whatsoever will Kaspersky provide intelligence or law enforcement agencies that have a mandate and/ or capability for cyber-offensive operations with access to the Transparency Centre. The security information and infrastructure in the Transparency Centre are provided by Kaspersky strictly for consultation purposes only. Any actions to modify the company's source code, software updates, or threat detection rules are forbidden and will be prevented by the TC Steering team; any abuse will be reported to the local law enforcement agency" (Kaspersky Lab 2019b). 
10 According to Eugene Kaspersky, "[t]ransparency is becoming the new normal for the IT industry - and for the cyber security industry in particular" (Business Wire 2018).

11 In April 2019, for example, Charter of Trust partners met to discuss the latest developments around the EU Cybersecurity Act with Despina Spanou, the responsible representative of the European Commission, and presented their proposals for next steps and further action (see Siemens 2019b).

12 Referring to their endeavors as Charter, Accord, Manifesto, or Convention underscores the underlying political ambitions of these actors.

\section{References}

All links checked on August 23, 2021.

Abbott, K. W., and Snidal, D. (2000). Hard and Soft Law in International Governance. International Organization, 54(3): 421-456.

Barlow, J. P. (1996). A Declaration of the Independence of Cyberspace. Retrieved from: https://perma.cc/DRJ9-WEGT.

Björkdahl, A (2002). Norms in International Relations: Some Conceptual and Methodological Reflections. Cambridge Review of International Affairs, 15(1): 9-23.

Black, J. (2017). "Says Who?" Liquid Authority and Interpretive Control in Transnational Regulatory Regimes. International Theory, 9(2): 286-310.

Business Wire. (2018, November 13). Kaspersky Lab Starts Data Processing for European Users in Zurich and Opens Its First Transparency Center. Retrieved from: https:// www.businesswire.com/news/home/20181113005169/en/Kaspersky-Lab-Starts-Data -Processing-European-Users.

Carbonara, E. (2017). Law and Social Norms. In F. Parisi (ed.), Columbia Law Review. Vol. 1. Oxford: Oxford University Press.

Charney, S., English, E., Kleiner, A., Malisevic, N., McKay, A., Neutze, J., and Nicholas, P. (2016). From Articulation to Implementation: Enabling Progress on Cyber Security Norms. Microsoft. Retrieved from: https:/query.prod.cms.rt.microsoft.com/cms/api/ am/binary/REVmc8.

Council of the European Union. (2019, April 12). Declaration by the High Representative on Behalf of the EU on Respect for the Rules-Based Order in Cyberspace. Press Releases. Retrieved from: https://www.consilium.europa.eu/en/press/press-releases /2019/04/12/declaration-by-the-high-representative-on-behalf-of-the-eu-on-respect-for -the-rules-based-order-in-cyberspace/.

Dobrygowski, D. (2019, September 11). Why Companies Are Forming Cybersecurity Alliances. Harvard Business Review. Retrieved from: https://hbr.org/2019/09/why -companies-are-forming-cybersecurity-alliances.

Dunn Cavelty, M., and Wenger, A. (2020). Cyber Security Meets Security Politics: Complex Technology, Fragmented Politics, and Networked Science. Contemporary Security Policy, 41(1): 5-32.

EastWest Institute. (2019, February 7). Global Commission's Cyber Stability Hearings at the UN. News. Retrieved from: https://www.eastwest.ngo/idea/global-commissions -cyber-stability-hearings-un.

European Commission. (2018). Charter of Trust for a Secure Digital World. Announcements. Retrieved from: https://ec.europa.eu/commission/commissioners/2014-2019/bienkowska /announcements/charter-trust-secure-digital-world_en. 